\title{
Public drug policy for children in Canada
}

\author{
Avram E. Denburg MD MSc, Wendy J. Ungar MSc PhD, Mark Greenberg MBChB
}

Cite as: CMAJ 2017 July 31;189:E990-4. doi: 10.1503/cmaj.170380

$\mathbf{R}$ ecent efforts have helped reform the global landscape of drug development to incorporate the unique needs of children into research and regulation. ${ }^{1}$ However, an area of persistent inadequacy is public policy on funding for pediatric drugs, which varies widely by jurisdiction. Health systems are increasingly faced with the competing pressures of resource scarcity and innovation. In this environment, emphasis on the comparative value of health interventions is prominent in health policy and system stewardship in most developed nations, including Canada.

Health technology assessment frameworks appraise the costeffectiveness and wider aspects of the value of "technologies" (i.e., drugs, devices, procedures or services) to inform policy decision-making and resource allocation within publicly funded health systems. ${ }^{2}$ As health technology assessment processes have become standardized, challenges have surfaced in the evaluation of therapies for children. Most health technology assessment has focused on adult health. Child health receives little attention, in part, because of lower disease prevalence and the challenges associated with including children in clinical research. ${ }^{3}$ There is also growing awareness that health technology assessment as currently conducted presents many conceptual and practical problems in its application to child health. ${ }^{4}$

The poor fit of health technology assessment to the realities of childhood disease and development has abetted an erratic approach to assessing public funding for pediatric drugs, and has potentiated a patchwork of coverage across Canada (Table 1). ${ }^{5} \mathrm{~A}$ national, child-focused policy framework for public drug regulation and funding that recognizes regional concerns and values is essential to correct these shortcomings. We analyze the limitations and challenges presented by prevailing health technology assessment frameworks with respect to children, explore their links to existing market and regulatory realities, and consider potential policy solutions.

\section{Current challenges}

\section{System limitations}

Canadian processes for appraising health technologies do not take into account the unique characteristics of children and the scientific evidence pertaining to drug indications and utilization in this population. Data concerning new drugs being brought to market are first submitted to Health Canada for approval of safety and efficacy to permit sale in Canada. Once approved, pro-

\section{KEY POINTS}

- Making decisions about public funding for drugs for children is uniquely challenging.

- Health technology assessment frameworks need better ways to incorporate the unique evidentiary, economic and ethical dimensions of child health.

- Canada needs a child-focused national policy framework for drug funding that reflects partnerships between industry, provincial governments and health-system stakeholders to entrench reliable and equitable processes for evaluating child health technologies.

vided consideration for public funding is desired, a submission is made to the national-level health technology assessment organization, the Canadian Agency for Drugs and Technologies in Health (CADTH), which "reviews drugs and makes reimbursement recommendations to Canada's federal, provincial, and territorial public drug plans, with the exception of Quebec, to guide their drug funding decisions." Some provinces perform a provincial review, often resulting in different coverage across the country (Figure 1). ${ }^{7}$

Evaluation of a novel drug by either national or provincial committees for a pediatric indication is uncommon; typically, funding recommendations are based on adult indications. This is predominantly due to the industry-driven submission process: in most cases, drug licensing and funding submissions are made by manufacturers or by contract research organizations on their behalf.

The lack of attention to child health technology assessment is partly a consequence of market dynamics. Children typically represent a small fraction of the potential market for a given drug. These limited markets are further fragmented by unique disease biology and special formulation requirements for children. More complex still, some drugs have a similar indication across age groups, albeit with varying evidence of efficacy; others have entirely different disease indications in adults and children; and still others are indicated for use in children only. ${ }^{8}$ These factors deter industry from generating evidence on the safety and efficacy of novel therapies in children, and by corollary, the submission of cost-effectiveness evidence of such therapies for pediatric health technology assessment review.

Canada lags behind the United States and Europe in regulatory provisions related to pediatric drug development. These jurisdictions have legislated both carrot-and-stick mechanisms 
to induce drug companies to study and market pediatric indications for their drugs. ${ }^{9}$ These mechanisms involve, on the one hand, governmental perogative to mandate pediatric studies, and, on the other, the extension of market exclusivity in exchange for the conduct of such studies. The lack of comparable provisions in Canada has abetted a sizable gap in the submission of pediatric trial data to Health Canada compared with the US Food and Drug Administration. ${ }^{8}$

Compounding the problem posed by new drugs, most existing drugs lack approved pediatric indications, making off-label prescribing the norm rather than the exception. ${ }^{10}$ There are no routine mechanisms to incentivize or compel the review of drugs already on the market for adult indications for extending public funding recommendations to relevant pediatric indications. Although permitted by CADTH, submissions by providers or patient groups for either new or existing drugs are uncommon, in large part because of the demands of such submissions, which require the compilation and analysis of detailed clinical and pharmacoeconomic evidence.

Finally, in an environment with limited institutional and financial resources, setting priorities on which drugs undergo health technology assessment review determines which drugs get publicly funded. Again, such processes often disadvantage children: some of the most prevalent principles employed to prioritize therapies for review - including disease burden, economic impact, strength of evidence and expected level of interest - are at odds with the epidemiologic and evidentiary realities of childhood diseases. ${ }^{11}$

\section{Methodologic limitations}

There are conceptual challenges to applying health technology assessment to child health that are distinct from the system-level challenges to child-focussed drug reviews. The adjudication of drugs and other health technologies for public coverage in Canada and abroad is premised on three major domains: evidence of safety and clinical effectiveness, value for money and ethics. The relative weight afforded the items within each domain, and the manner in which they are integrated, vary across jurisdictions; however, the overall parameters of assessment are similar. ${ }^{12}$ In most instances, the normative assumptions present in these domains introduce bias against positive funding recommendations for children.

Evidence-based medicine ranks methods of inquiry by their susceptibility to bias; systematic reviews and meta-analyses of data from randomized clinical trials (RCTs) are considered the most important. ${ }^{13}$ There is strong epistemological justification for this approach in most adult disease, but it is not useful for pediatrics. Clinical trials in children are constrained by small populations, and further reduced in the age of genomic classification of disease nosology, the complexities of trial enrolment of children and weak industry interest in pediatric drug development. ${ }^{14,15}$ Although the child health community has worked hard to overcome these barriers through collaborative research agendas, destigmatization of pediatric research and advocacy in support of legislative reforms to regulatory environments for drug development, ${ }^{16}$ health technology assessment reviews of drugs for pediatric indications are often non-starters owing to a lack of acceptable high-quality evidence.

Table 1: Provincial and territorial drug programs that provide benefits to children*

\begin{tabular}{|c|c|c|c|c|c|c|c|c|c|c|c|c|c|}
\hline Program type & NL & PE & NS & NB & QC & ON & MB & SK & $A B$ & BC & YK & NWT & NU \\
\hline $\begin{array}{l}\text { Universal program for all residents } \\
\text { without private insurance (deductibles are } \\
\text { not income-indexed) }\end{array}$ & & & & $\sqrt{ }$ & $\sqrt{ }$ & $\sqrt{ } \dagger$ & & & $\sqrt{ }$ & & & & $\sqrt{\ddagger}$ \\
\hline Income-indexed drug plan & & & & & & & $\sqrt{ }$ & & & $\sqrt{ }$ & & & \\
\hline $\begin{array}{l}\text { Income-indexed catastrophic drug plan } \\
\text { for persons with very high costs relative to } \\
\text { income or transitional plan for persons } \\
\text { leaving social assistance }\end{array}$ & $\sqrt{ }$ & $\sqrt{ }$ & $\sqrt{ }$ & $\sqrt{ }$ & & $\sqrt{ }$ & & $\sqrt{ }$ & $\sqrt{\S}$ & & & & \\
\hline Social assistance/welfare & $\sqrt{ }$ & $\sqrt{ }$ & $\sqrt{ }$ & $\sqrt{ }$ & $\sqrt{ }$ & $\sqrt{ }$ & $\sqrt{ }$ & $\sqrt{ }$ & $\sqrt{ }$ & $\sqrt{ }$ & & & \\
\hline $\begin{array}{l}\text { Special family/child program for } \\
\text { low-income families }\end{array}$ & $\sqrt{ }$ & $\sqrt{ }$ & & & & & & $\sqrt{ }$ & $\sqrt{ }$ & & $\sqrt{ }$ & & \\
\hline \multicolumn{14}{|l|}{ Specific program for: } \\
\hline Cystic fibrosis & $\sqrt{ }$ & $\sqrt{ }$ & & $\sqrt{ }$ & & $\sqrt{ }$ & & & & $\sqrt{ }$ & & & \\
\hline Diabetes & & $\sqrt{ }$ & & $\sqrt{ }$ & & & & & & & & & \\
\hline Human growth hormone & $\sqrt{ }$ & $\sqrt{ }$ & & $\sqrt{ }$ & & & & & & & & & \\
\hline Children with severe disabilities & & & $\sqrt{ }$ & $\sqrt{ }$ & & $\sqrt{ }$ & & & & $\sqrt{ }$ & $\sqrt{ }$ & & \\
\hline Umbrella program for chronic disease & & & & & & $\sqrt{ }$ & & $\sqrt{ }$ & $\sqrt{ }$ & & $\sqrt{ }$ & $\sqrt{ }$ & $\sqrt{ }$ \\
\hline \multicolumn{14}{|c|}{$\begin{array}{l}\text { Note: } A B=\text { Alberta, } B C=\text { British Columbia, } M B=\text { Manitoba, NB = New Brunswick, NL = Newfoundland, NS = Nova Scotia, NU = Nunavut, NWT = } \\
\text { PE = Prince Edward Island, QC = Quebec, SK = Saskatchewan, YK = Yukon. } \\
\text { *Programs described are those in effect as of April } 2015 \text { except where indicated. } \\
\text { †The Ontario universal pharmacare program is for all residents under } 25 \text { years of age, regardless of insurance status; effective January } 2018 . \\
\text { FFor children who are registered Indigenous or Inuit, or infants of parents that meet these criteria. } \\
\text { §Alberta's transitional program is not income-indexed and does not require cost sharing. }\end{array}$} \\
\hline
\end{tabular}


Standard methods for economic evaluation in health technology assessment also do not capture distinguishing features of child health and illness. ${ }^{17}$ Principal among these is a lack of sensitivity to life-course dynamics. Lack of data prohibits incorporation of recommended outcome metrics, such as quality-adjusted life years (QALYs), into models that assess the aggregate benefits and burdens of a given treatment over a lifetime. ${ }^{18}$ This is shown in the current proliferation of novel biologic and immunomodulatory therapies: there is little knowledge of the developmental and late effects of many new drugs that are brought to market, which complicates efforts to accurately assign long-term benefits and costs associated with their use in children. In addition, there are few child-specific, preference-based measures of quality of life, which compromises the calculation of QALYs for use in cost-utility analyses that form the backbone of health technology assessment.

The instruments developed to elicit health-state utilities in children often rely on parental proxies for young children. There is also almost no systematic incorporation - either in theory or in practice - of the economic impacts of a child's illness and treatment on the family. ${ }^{19}$ Dependency is a critical component of virtually all childhood experience of illness that is almost never captured in pharmacoeconomic models. The current Guidelines for the Economic Evaluation of Health Technologies from CADTH do not acknowledge these issues. The absence of data is viewed as a form of uncertainty to be handled through probabilistic analysis or consultation with experts. ${ }^{20}$
Ethical dilemmas are bound up in these approaches to evidence generation and economic modelling. The value of a year at any given point along a life path is commonly assumed to be constant: a QALY gained at age 2 years is routinely deemed equivalent to a QALY gained at 72 years of age..$^{21,22}$ The moral legitimacy of this calculus may differ across societies..$^{23}$ Indeed, many societies may value health gains in children more highly than in adults for many reasons: the social and economic costs of squandered potential; a belief in "fair innings," or the value of comparable opportunities to experience life; and the intrinsic value placed on childhood itself. ${ }^{24-27}$ Social values may also dictate a preference to allocate scarce resources to those who are more vulnerable. ${ }^{28}$ Children are vulnerable in multiple ways: they may incur intergenerational socioeconomic disparity, they cannot advocate for themselves, and they are usually sociopolitically disenfranchised. These dynamics have equity implications for the systems constructed to conduct such drug appraisals. These systems must include the unique social values that are involved in drug appraisal and funding for children.

\section{Potential solutions}

Developing a cohesive national framework to guide policy-making on access to drugs for children is critical for addressing the shortcomings described previously. This would strengthen the
Industry

Regulator

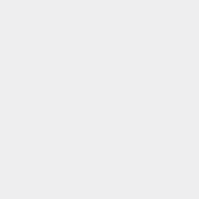

National HTA

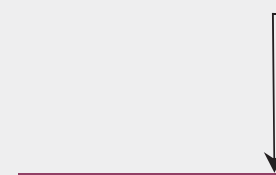

Health Canada - Oncology drugs: NCE/new combination/new indication - $p E R C$ recommendation to drug plans
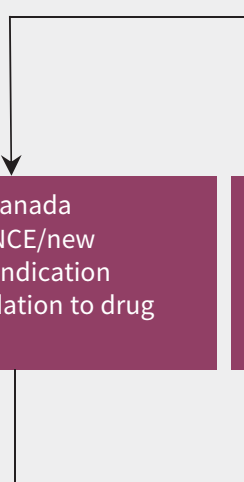

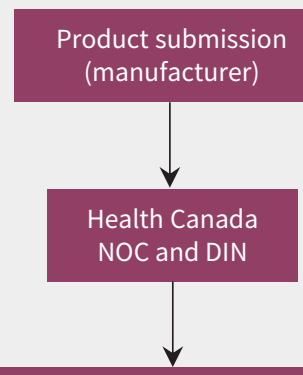

Product submission (usually the manufacturer)

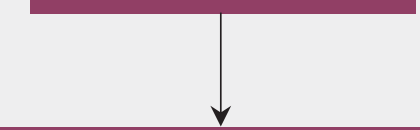

CADTH: CDR

- NCE/new combination/new

indication

- CDEC recommendation to drug plans

Provincial policy/payers

Province-specific approval processes pan-Canadian Pharmaceutical Alliance negotiations

Figure 1: Drug approval and funding process in Canada (except in Quebec). Note: $\mathrm{CADTH}=$ Canadian Agency for Drugs and Technologies in Health, $\mathrm{CDEC}=\mathrm{Cana}-$ dian Drug Expert Committee, $\mathrm{CDR}=$ common drug review, DIN = drug identification number, HTA = health techology assessment, NCE = new chemical entity, $\mathrm{NOC}=$ notice of compliance - approval of drug safety and efficacy, $\mathrm{pCODR}=$ pan-Canadian Oncology Drug Review, pERC $=$ pCODR Expert Review Committee. 
technical and moral bases of decisions on drug funding and would help rationalize these decisions across provinces, thereby providing more unified and equitable access to new and existing drugs for children.

This framework should consider determinants of access from product development through to funding. Two components are integral: reform of the drug regulatory system in favour of pediatric drug research and development, and federal stewardship and pan-provincial application of standards of drug funding for children. Federal legislation to incentivize and compel industry to conduct more pediatric drug research would help attenuate gaps in evidence on drug safety and efficacy in children. It could help set priorities for pediatric drug research, spur the development of databases from clinical trials to improve transparency and reduce redundancy, and enhance regulatory harmonization across jurisdictions. Federal support for efforts to develop a national network for pediatric clinical trials in Canada would help advance the evidence base for domestic health technology assessment reviews. ${ }^{29}$

There is also an opportunity for a strengthened federal role in supporting existing cross-provincial efforts to rationalize drug purchasing through the pan-Canadian Pharmaceutical Alliance. ${ }^{7}$ Establishment of the alliance has augmented provincial coordination in the uptake of recommendations on national health technology assessment and follow-on price negotiations with industry. These laudable provincial efforts proceed from national-level recommendations on drug funding. Therefore, the right fit of principles and methods for pediatric health technology assessment is essential to ensuring that pediatric drugs are covered and at prices calibrated to their value.

Expanding the CADTH guidelines to include the conduct of health technology assessment in children would establish a universal benchmark for the conduct and adjudication of national and provincial drug reviews for pediatric indications. The use of such guidelines could be strengthened by mandating that all national-level reviews incorporate an explicit assessment of the clinical evidence, and social and economic impacts of the funding recommendation related to children. National legislation could both require and empower national health technology assessment bodies to commission industry submissions on drugs for pediatric indications, and compel or incent industry to submit them.

The success of these efforts will depend on careful incorporation of evidentiary, economic and ethical principles that are geared to the realities of child health. As with uncommon diseases, creative approaches to trial design and evidence appraisal - including adaptive designs and access with concurrent evidence development - are needed. ${ }^{30}$ Health Canada has an important role to play as a steward of the system for pediatric drugs. It will need to work with industry and academia to facilitate innovative pediatric trials in Canada, augment market authorization for pediatric indications and equip health technology assessment bodies with the authority and resources to track postmarket use to revise appraisals in line with real-world evidence. Canadian health technology assessment bodies will need to adapt health economic models to encompass familial, developmental and life-course impacts. Because ideal models will be tempered by on-the-ground realities of data availability and system pressures, methods to ensure the incorporation of perspectives of those involved in or impacted by childhood illness should be strengthened. Many health technology assessment institutions already give voice to patient values and experiences in their drug assessments; such endeavours could be strengthened through the routine use of public engagement, such as citizen panels. ${ }^{31}$ Health technology assessment institutions could also prioritize the incorporation of pediatric-specific clinical expertise in their clinical and economic reviews.

\section{Conclusion}

Regulatory and health technology assessment systems in Canada give little regard to the unique features of child health. This has abetted an ad hoc approach to public funding decisions for pediatric drugs. Canada must create an integrated public policy framework on decision-making for drug regulation for children that is adequately funded. This will require the development and application of a coherent set of standards for appraising child health technologies, national stewardship to facilitate partnerships among key stakeholders and provincial coordination in the adoption of pan-Canadian funding recommendations.

\section{References}

1. Finney E. Children's medcines: a situational analysis. Geneva: World Health Organization; 2011. Available: www.who.int/childmedicines/progress/CM_ analysis.pdf?ua=1 (accessed 2017 June 2).

2. What is health technology assessment (HTA)? [main page]. Edmonton: International Network of Agencies for Health Technology Assessment (INAHTA). Available: www.inahta.org/ (accessed 2017 Mar. 10).

3. Ungar WJ, Prosser LA, Burnett HF. Values and evidence colliding: health technology assessment in child health. Expert Rev Pharmacoecon Outcomes Res 2013;13:417-9.

4. Costa V, Ungar WJ. Health technology assessment in child health. In: Ungar WJ, editor. Economic Evaluation in Child Health. Oxford (UK): Oxford University Press; 2009.

5. Primary health care services for children and youth in Canada: access, quality and structure. Section 5: other primary health care services. Ottawa: Canadian Institute of Child Health; 2015. Available: http://profile.cich.ca/en/index.php/ chapter3/section-5-other-primary-care-services/406 (accessed 2017 June 26).

6. Programs and services. Ottawa: Canadian Agency for Drugs and Technologies in Health. Available: https://www.cadth.ca/about-cadth/what-we-do/products -services (accessed 2017 Mar. 20).

7. The pan-Canadian Pharmaceutical Alliance. Ottawa: Council of the Federation; 2016. Available: www.pmprovincesterritoires.ca/en/initiatives/358-pan-canadian -pharmaceutical-alliance (accessed 2017 June 1).

8. Improving medicines for children in Canada: The Expert Panel on Therapeutic Products for Infants, Children, and Youth. Ottawa: Council of Canadian Academies; 2014. Available: www.scienceadvice.ca/uploads/eng/assessments $\% 20$ and\%20publications\%20and\%20news\%20releases/therapeutics/therapeutics_ fullreporten.pdf (accessed 2017 Mar. 10).

9. Rieder MJ; Canadian Paediatric Society, Drug Therapy and Hazardous Substances Committee. Drug research and treatment for children in Canada: a challenge. Paediatr Child Health 2011;16:560-1.

10. Palmaro A, Bissuel R, Renaud N, et al. Off-label prescribing in pediatric outpatients. Pediatrics 2015;135:49-58.

11. Noorani HZ, Husereau DR, Boudreau R, et al. Priority setting for health technology assessments: a systematic review of current practical approaches. Int $J$ Technol Assess Health Care 2007;23:310-5.

12. Stafinski T, Menon D, Philippon D, et al. Health technology funding decision-making processes around the world: the same, yet different. Pharmacoeconomics 2011;29:475-95. 
13. Ashcroft RE. Current epistemological problems in evidence-based medicine. J Med Ethics 2004;30:131-5.

14. Kodish E, editor. Ethics and research with children: a case-based approach. New York: Oxford University Press; 2005.

15. Milne CP, Bruss JB. The economics of pediatric formulation development for off-patent drugs. Clin Ther 2008;30:2133-45.

16. Hoppu K, Anabwani G, Garcia-Bournissen F, et al. The status of paediatric medicines initiatives around the world - What has happened and what has not? Eur J Clin Pharmacol 2012;68:1-10.

17. Ungar WJ, Gerber A. The uniqueness of child health and challenges to measuring costs and consequences. In: Ungar WJ, editor. Economic evaluation in child health. Oxford (UK): Oxford University Press; 2010:3-32.

18. Keren R, Pati S, Feudtner $C$. The generation gap: differences between children and adults pertinent to economic evaluations of health interventions. Pharmacoeconomics 2004;22:71-81.

19. Ungar WJ. Challenges in health state valuation in paediatric economic evaluation: Are QALYs contraindicated? Pharmacoeconomics 2011;29:641-52.

20. Guidelines for the economic evaluation of health technologies: Canada. 4th ed. Ottawa: Canadian Agency for Drugs and Technologies in Health; 2017. Available: https://www.cadth.ca/about-cadth/how-we-do-it/methods-and -guidelines/guidelines-for-the-economic-evaluation-of-health-technologies -canada (accessed 2017 Mar. 30).

21. Weinstein MC. A QALY is a QALY is a QALY - Or is it? J Health Econ 1988;7: 289-90.
22. Brock DW, Daniels N, Neumann PJ, et al. Ethical and distributive considerations. In: Neumann PJ, Ganiats TG, Russell LB, et al., editors. Cost-effectiveness in health and medicine. 2nd ed. Oxford (UK): Oxford University Press; 2016;319-42.

23. Donaldson $\mathrm{C}$, Baker $\mathrm{R}$, Mason $\mathrm{H}$, et al. The social value of a QALY: Raising the bar or barring the raise? BMC Health Serv Res 2011;11:8.

24. Nord E, Street A, Richardson J, et al. The significance of age and duration of effect in social evaluation of health care. Health Care Anal 1996;4:103-11.

25. Gormley W. Voices for children: rhetoric and public policy. Washington: Brookings Institution Press; 2012.

26. Williams A. Intergenerational equity: an exploration of the 'fair innings' argument. Health Econ 1997;6:117-32.

27. Mayall B. Values and assumptions underpinning policy for children and young people in England. Child Geogr 2006;4:9-17.

28. Petrou S. Should health gains by children be given the same value as health gains by adults in an economic evaluation framework? In: Ungar WJ, editor. Economic evaluation in child health. Oxford (UK): Oxford University Press; 2010:71-87.

29. Best practices for health research involving children and adolescents: genetic, pharmaceutical and longitudinal studies. Montréal: Centre of Genomics and Policy; and Vancouver: Maternal Infant Child and Youth Research Network; 2012.

30. Abrahamyan L, Feldman BM, Tomlinson G, et al. Alternative designs for clinical trials in rare diseases. Am J Med Genet C Semin Med Genet 2016;172:313-31.

31. Abelson J, Giacomini M, Lehoux P, et al. Bringing the 'public' into health technology assessment and coverage policy decisions: From principles to practice. Health Policy 2007;82:37-50.

\section{Competing interests: None declared.}

Affiliations: Division of Haematology/Oncology (Denburg, Greenberg); Child Health and Evaluative Sciences (Denburg, Ungar), Peter Gilgan Centre for Research and Learning, The Hospital for Sick Children; Institute for Health Policy, Management and Evaluation (Ungar), University of Toronto; Pediatric
Oncology Group of Ontario (Greenberg), Toronto, Ont.

Contributors: Avram Denburg and Mark Greenberg had the initial idea for the article. All of the authors collaborated on the development of core concepts. Avram Denburg wrote the first draft of the manuscript. Wendy Ungar and Mark Greenberg provided substantive edits and revised it for important intellectual content. All of the authors gave final approval of the version to be published and agreed to be accountable for all aspects of the work.

This article has been peer reviewed.

Correspondence to: Avram Denburg, avram. denburg@sickkids.ca 